\title{
Comparing depth-dependent curing radiant exposure and time of curing of regular and flow bulk-fill composites
}

\section{Jose Augusto RODRIGUES(a) llana Pais TENORIO(a) \\ Ginger Baranhuk Rabello de MEUO(a) \\ André Figueiredo REIS(a) \\ Chiayi SHEN(b) \\ Jean-François ROULET ${ }^{(b)}$}

(a) Universidade Guarulhos - UNG, Department of Restorative Dentistry, Dental Research and Graduate Studies Division, Guarulhos, SP, Brazil.

(b) University of Florida, College of Dentistry, Department of Restorative Dental Sciences, Gainesville, FL, United States of America.

Declaration of Interest: The authors certify that they have no commercial or associative interest that represents a conflict of interest in connection with the manuscript.

Corresponding Author:

Jose A Rodrigues

E-mail: jose.rodrigues@ung.br

hitps://doi.org/10.1590/1807-3107BOR-2017.vol31.0065

Submitted: Jan 30, 2017

Accepted for publication: May 22, 2017

Last revision: June 01, 2017
Abstract: The effect of restoration depth on the curing time of a conventional and two bulk-fill composite resins by measuring microhardness and the respective radiosity of the bottom surface of the specimen was investigated. 1-, 3- and 5-mm thick washers were filled with Surefil SDR Flow-U (SDR), Tetric EvoCeram Bulk Fill-IVA (TEC) or Esthet-X HD-B1 (EHD), and cured with Bluephase ${ }^{\circledR}$ G2 for 40s. Additional 1-mm washers were filled with SDR, TEC or EHD, placed above the light sensor of MARC ${ }^{\circledR}$, stacked with pre-cured 1-, 3- or 5-mm washer of respective material, and cured for 2.5 60s to mimic 2-, 4- and $6-\mathrm{mm}$ thick composite curing. The sensor measured the radiosity $\left(\mathrm{E}_{\mathrm{B}}\right)$ at the bottom of specimen stacks. Vickers hardness (VH) was measured immediately at 5 locations with triplicate specimens. Nonlinear regression of $\mathrm{VH}$ vs $\mathrm{E}_{\mathrm{B}}$ by $\mathrm{VH}=\alpha\left[1-\exp \left(-\mathrm{E}_{\mathrm{B}} / \beta\right)\right]$ with all thickness shows that the values of $\alpha$, maximum hardness, are $21.6 \pm 1.0 \mathrm{~kg} / \mathrm{mm}^{2}$ for SDR, $38.3 \pm 0.6 \mathrm{~kg} / \mathrm{mm}^{2}$ for TEC and $45.3 \pm 2.6 \mathrm{~kg} / \mathrm{mm}^{2}$ for EHD, and the values of $\beta$, rate parameter, are $0.40 \pm 0.06 \mathrm{~J} / \mathrm{cm}^{2}$ for SDR, $0.77 \pm 0.04 \mathrm{~J} / \mathrm{cm}^{2}$ for TEC and $0.58 \pm 0.09 \mathrm{~J} / \mathrm{cm}^{2}$ for EHD. The radiosity of the bottom surface was calculated when the bottom surface of each material attained $80 \%$ of $\alpha$ of each material. The curing times for each material are in agreement with manufacturer recommendation for thickness. It is possible to estimate time needed to cure composite resin of known depth adequately by the radiosity and microhardness of the bottom surface.

Keywords: Composite Resins; Polymerization.

\section{Introduction}

Dentin bonding capability and aesthetic quality of resin composites have led to their increased use in restorative dentistry. ${ }^{1}$ However, there are some concerns in class II restorations with deep proximal boxes with respect to the degree of monomer conversion and polymerization shrinkage strain. ${ }^{2}$ To reduce the inherent polymerization shrinkage, and achieve adequate curing of the resin, composite resins must be inserted by an incremental oblique layering technique. ${ }^{2}$ In addition, the duration of light activation needs to be increased for deep cavities to make up the increased light scattering caused by the depth of the restoration to assure proper cure of the composite resin at the bottom..$^{2,3,4}$ These procedures increase the chair time and the risk of saliva contamination between increments. ${ }^{5}$ 
A new category of resin composites was introduced for bulk-filling deep and wide dental cavities providing a faster and easier procedure than the traditional incremental restoration technique. $4,5,6,7,8,9,10,11$ Manufactures state that bulk-fill resin composites could be placed up to 4 or $5 \mathrm{~mm}$ thick layers skipping the time-consuming layering process, and cured with light exposure time of up to $20 \mathrm{~s}$.

Literature has shown that bulk-filling with conventional composite resin resulted in lower values of hardness, especially at the cervical surfaces of class II restorations. ${ }^{2}$ It was the lower radiant flux at the deepest layers that led to compromise of efficacy of polymerization. ${ }^{1,2,3,4}$ To reduce these limitations, the bulk-fill resin composites are designed to have increased depth of cure through higher translucency or by addition of new, more efficient photoinitiators. Furthermore, lower shrinkage is achieved by modifying monomers, and reducing filler size. ${ }^{6,7,7,9,10}$ However, conflicting results of maximal incremental thickness of bulk-fill resin composites are still being reported. A systematic review showed that high-viscosity viscosity bulk-fill resin composites are partially properly cured in $4 \mathrm{~mm}$ of cavity depth measured by depth of cure and / or degree of conversion. ${ }^{12}$ Several issues may affect the polymerization efficiency of bulk fill composite resins, and the variability on the results of the authors was mainly dependent on the bulk fill composite resin brand evaluated and time of photo activation. Also, some studies used over or under exposure time. ${ }^{3,6,13,14,15}$ According to Tarle et al., ${ }^{16}$ minimum curing times recommended by the manufacturers is not adequate for placement of high-viscosity bulk-fill materials.

Laboratory research generally shows that between 12 and $24 \mathrm{~J} / \mathrm{cm}^{2}$ of radiant exposure is needed to cure a 2-mm thick layer of resin composites adequately.17,18 In fact, depending on the brand and shade, as much as $36 \mathrm{~J} / \mathrm{cm}^{2}$ has been reported to adequately cure some resin composites. ${ }^{17}$ While manufacturers do not specify routinely the level of radiant exposure needed to cure their products adequately, it is possible to quantify the radiant exposure delivered to the surface of the composite resin to be cured, and the irradiance of the light that has passed through the specimen during material curing. This is possible by means of a device comprising a light sensor capturing light from the light curing unit and a sensor at the bottom of the specimen being cured, both connected to a spectrometer analyzing the captured light. Measurements of microhardness at the top and the bottom of the specimen could then determine if the entire specimen is cured adequately. ${ }^{19}$ The information generated would complement the published data on the characteristic of curing bulk-fill resin composites.

The objective of this study is to test the null hypothesis that there is no difference among the three categories of resin composites investigated in the effect of curing depth on the radiant exposure required for curing. One regular-viscosity bulk-fill, one low-viscosity bulk-fill composite resin, and one conventional composite resin were used as representatives of the three categories of resin composites.

\section{Methodology}

The resin composites investigated were Tetric EvoCeram Bulk-fill (TEC), a regular-viscosity bulk-fill composite resin (Ivoclar Vivadent, Schaan, Liechtenstein), Surefil SDR Flow (SDR), a low-viscosity bulk-fill composite (Dentsply Caulk; Milford, DE, USA), and Esthet-X HD (EHD), a nanohybrid composite (Dentsply Caulk; Milford, DE, USA) as control (Table 1).

Delrin $^{\circledast}$ washers (outer diameter: $19 \mathrm{~mm}$; inner diameter: $6.4 \mathrm{~mm}$ ) with 1,3 and $5 \mathrm{~mm}$ thickness were filled with TEC, SDR, or EHD, covered with Mylar ${ }^{\circledR}$ strips on both sides and then pressed between two glass plates by hand pressure to expel excess material which was removed to assure the thickness of the composite material in washer. Each filled washer was cured with a light curing unit Bluephase ${ }^{\circledR}$ G2 (Irradiance: $1,275 \mathrm{~mW} / \mathrm{cm}^{2}$, Ivoclar Vivadent, Schaan, Liechtenstein) for $40 \mathrm{~s}$. The procedure yielded nine standard composite filled washers; they were 1-mm, 3-mm and 5-mm thick of cured composite discs for each of the three materials investigated for later use.

\section{Measurement of radiosity at the bottom surface of the specimen}

A MARC ${ }^{\circledast}$ Resin Calibrator (BlueLight Analytics, Halifax, Canada) was used to measure radiant energy emitted at the bottom surface of the specimen as each 
Table 1. Materials manufactures, batch number, and components used in this study.

Material, batch number

SDR - SureFil SDR Flow - Shade U

(Dentsply Caulk, Milford, DE, USA)

1407292

TEC- Tetric EvoCeram Bulk

Fill - Shade IVA (lvoclar Vivadent,

Schaan, Liechtenstein) T29056

EHD- Esthet-X HD - Shade B1

(Dentsply Caulk, Milford, DE, USA)

130609

\section{Components*}

Modified UDMA, EBPADMA, TEGDMA, CQ, butylated hydroxyl tolvene, uv stabilizer, titanium oxide, iron oxide pigments. Barium-alumino-fluoro-borosilicate glass, strontium alumino-fluoro-silicate glass, $4.2 \mu \mathrm{m}$ mean particle size, $68 \mathrm{w}+\%$.

Bis-GMA, UDMA, Bis-EMA, EBPADMA, stabilizers, Ivocerin, CQ and TPO, and prepolymer additives. Ytterbium trifluoride barium glass filler, mixed oxide, $550 \mathrm{~nm}$ mean particle size, $79-81 \mathrm{wt} \%$.

Bis-GMA, Bis-EMA, TEGDMA, CQ, Stabilizer, pigments. Barium fluoroborosilicate glass (0.8-0.6 $\mu \mathrm{m})$, nanofiller $(0.04 \mu \mathrm{m})$ silica, $72 \mathrm{w}+\%$.

UDMA: urethane dimethacrylate; EBPADMA: ethoxylated bisphenol-A dimethacrylate; TEGDMA: triethylene glycol dimethacrylate; $\mathrm{CQ}$ : camphorquinone; Bis-GMA: bisphenol-glycidyl methacrylate; Bis-EMA: bisphenol A polyethylene glycol diether dimethacrylate; T; PO: 2,4,6- trimethylbenzoyl diphenylphosphine oxide.

specimen being cured, which is the radiant energy (in $\mathrm{J} / \mathrm{cm}^{2}$ ) passing through respective composite over the time of exposure and called radiosity of the bottom surface $\left(\mathrm{E}_{\mathrm{B}}\right)$. Radiosity in radiometric term is defined as the radiant flux leaving, as by emission, reflection or transmission, a surface per unit area. The position of light curing unit relative to the light sensor was determined first by placing curing unit flush with the sensor and then moved the curing unit in $x-y$ plane to determine the location of highest irradiance. When the location was found, the unit was fixed on $x-y$ plane with $z$-axis free to move up or down to accommodate placement of composite specimens. The procedure was repeated if the curing unit position was disturbed.

A Mylar ${ }^{\circledast}$ strip was placed on the light sensor of MARC followed by a 1-mm thick Delrin washer to be filled with one of the three materials investigated. The inner space of the washer is perfectly aligned with the dimension of the light sensor. After filling, another piece of Mylar strip was placed on top of the composite in the washer and pressed to expel excess. 1-mm thick pre-cured Delrin washer filled with respective composite was laid on top of the first washer yielding a total of $2 \mathrm{~mm}$ thick of composite on top of the light sensor. This arrangement mimicked 2-mm depth of composite being exposed to a curing light and the radiosity measured at the bottom of the specimen stack by MARC. The 3-mm and 5-mm thick filled washer are to make $4 \mathrm{~mm}$ and $6 \mathrm{~mm}$ deep composite along with the 1-mm washer filled with uncured resin on top of the light sensor. This protocol (using discs of cured composite stacked on top of the composite disk being cured) was used to reduce the amount of resin composite needed.

Nine different exposure times $(2.5,5,10,15,20,25$, 30,40 , and $60 \mathrm{~s}$ ) with the Bluephase G2 were used for each thickness of resin composite. During the light exposure, the MARC recorded the irradiance exiting at the bottom of the specimen stacks in real time and converted them to radiosity. Three replications were tested for each resin composite (3), total thickness of the specimen stacks (3) and exposure time (9) combination for a total of $243(=3 \times 3 \times 3 \times 9)$ uncured specimens yielding 243 readings of radiosity.

\section{Microhardness evaluation}

The Vickers Hardness (VH) of the bottom surface of all specimens was measured immediately after irradiation with a microhardness tester (Micromet 3, Buehler Ltd, Lake Bluff, USA). The indentation load was $10 \mathrm{~g}$ and dwell time was $20 \mathrm{~s}$. Five indentations were made in each specimen, one in the center of surface, one each at $300 \mu \mathrm{m}$ to the top, bottom, left and right of the center indentation for a total of five indentation for each specimen.

\section{Data analysis}

When the values of $\mathrm{VH}$ measured of all thicknesses were plotted against respective values of $E_{B}$ for each material, it appeared that the hardness values were reaching a plateau as the radiosity increased, 
a characteristic of cumulative distribution function. The data were fitted into the following cumulative distribution function using SAS ${ }^{\circledR} 9.4$ (SAS, Cary, NC, USA) to determine the values of the plateau, which would be the maximum surface hardness $(\alpha)$ the bottom surface and the rate parameter $(\beta)$ each composite resin investigated:

$$
V H=a\left[1-\exp \left(-\frac{E_{B}}{\beta}\right)\right]
$$

Statistical differences of the value of $\alpha$ and $\beta$ were determined using ANOVA and Tukey HSD test.

The relationship between the values of $E_{B}$ and the radiant exposure times were found to exhibit linear relationship for each specimen thickness of all composite resins investigated. The radiant transmittance, ratio of irradiance transmitted to incident radiance delivered to the top of the specimen, could be calculated for each material and thickness. From eq. (1), we calculated the value of $E_{B}$ when the microhardness of the bottom surface reached $80 \%$, $90 \%, 95 \%$ and $99 \%$ of maximum microhardness. Because of the linear relationship between the value of $E_{B}$ and the radiant exposure time, the duration of curing time needed to yield prescribed value of microhardness for each thickness of each material were also calculated.

The irradiation exposure times needed to register that level of $E_{B}$ by MARC were calculated for each thickness of specimen and material by dividing the values of $E_{B}$ with the product of the respective percent of light transmission and the radiant exitance of the curing light.

\section{Results}

Figures 1-3 show the plots of the values of $\mathrm{VH}$ against respective values of $\mathrm{E}$ for each material. The best fit curves in Figure 1-3 represent the results of the non-linear regression. Non-linear regression of the experimental data yielded the values of maximum microhardness $(\alpha)$, rate parameter $(\beta)$ and degree of fit $\left(r^{2}\right)$ for each material investigated (Table 2). Linear relationship between $\mathrm{E}_{\mathrm{B}}$ and radiant exposure time was verified with the linear regression $\left(\mathrm{SAS}^{\circledR}{ }^{9.4}\right)$ and the results are shown in Table 3.

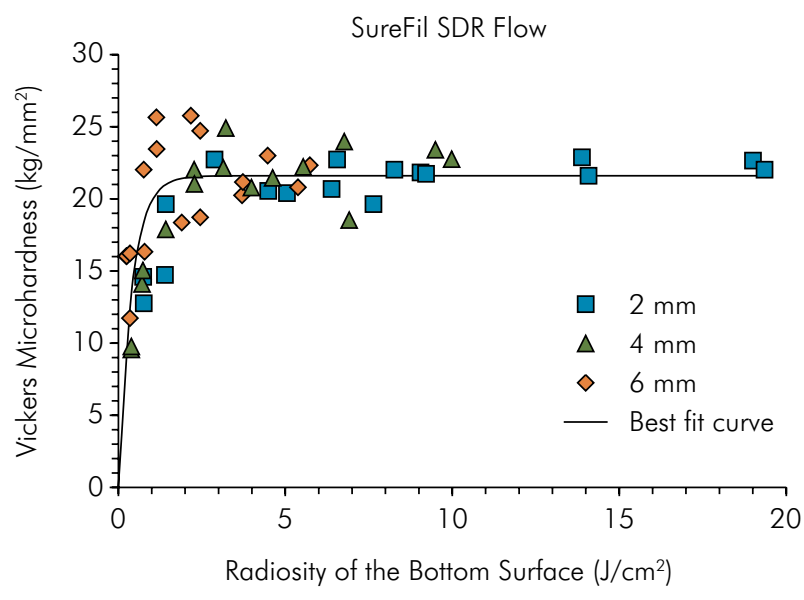

Figure 1. Non-linear regression of Radiosity of the Bottom Surface $\left(\mathrm{J} / \mathrm{cm}^{2}\right)$ and Vickers Microhardness $\left(\mathrm{kg} / \mathrm{mm}^{2}\right)$ for SureFil SDR Flow.

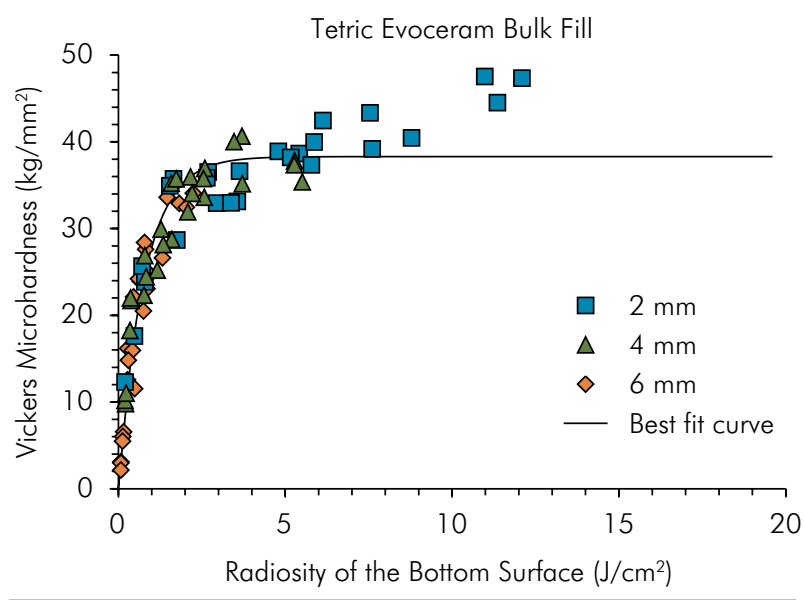

Figure 2. Non-linear regression of Radiosity of the Bottom Surface $\left(\mathrm{J} / \mathrm{cm}^{2}\right)$ and Vickers Microhardness $\left(\mathrm{kg} / \mathrm{mm}^{2}\right)$ for Tetric EvoCeram Bulk Fill.

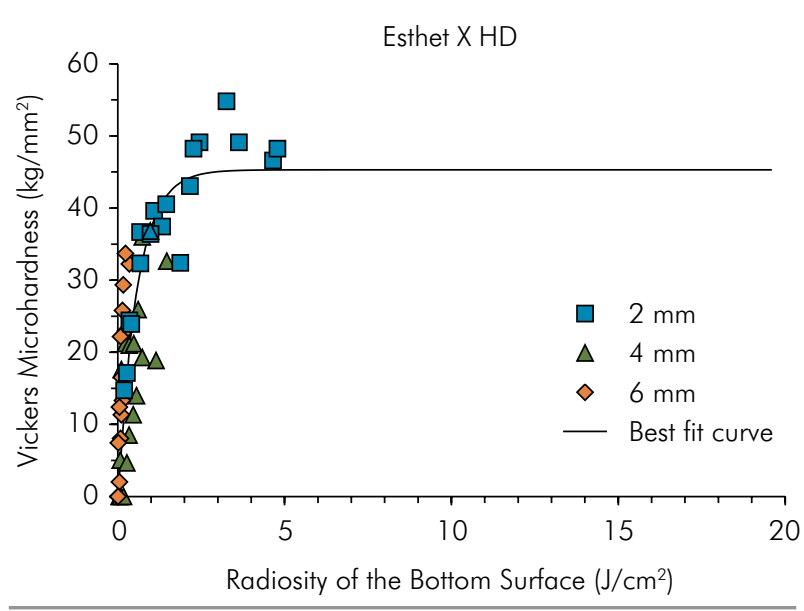

Figure 3. Non-linear regression of Radiosity of the Bottom Surface $\left(\mathrm{J} / \mathrm{cm}^{2}\right)$ and Vickers Microhardness $(\mathrm{kg} / \mathrm{mm} 2)$ for Esthet X HD. 
Analysis of variance shows that the values of $\alpha$ and $\beta$ are statistically significantly different among materials at $\mathrm{p}=0.0024$ and $\mathrm{p}=0.0388$, respectively. Tukey HSD tests showed that statistically significant difference exists only between SDR and EHD at $p=0.0017$ for $\alpha$ and at $p=0.0458$ for $\beta$. Using eq. (1) and the estimated values of $\alpha$ and $\beta$ for each material, we calculated the values of $E_{B}$ when the surface hardness of the bottom surface attain $80 \%, 90 \%, 95 \%$ and $99 \%$ of the maximum hardness values for each material (Table 2). The radiant transmittance (Table 3) for each thickness of specimen and material were calculated using the linear relationship between the value of $E_{B}$ and the radiant exposure time (Table 3).

The lowest optical trigger of the MARC unit was set at $11 \mathrm{~mW} / \mathrm{cm}^{2}$ by the manufacturer to reduce the influence of background noise. For the light curing unit with output of $1,275 \mathrm{~mW} / \mathrm{cm}^{2}$, the MARC unit would register only when the light transmission through the specimen is $>0.9 \%$. For $6 \mathrm{~mm}$ of EHD specimen, the value of $0.5 \%$ was an estimation based on the results of 2- and 4-mm thick specimens. The irradiation exposure times needed to register that level of $\mathrm{E}_{\mathrm{B}}$ (Table 2) by MARC were calculated for each thickness of specimen and material by dividing the values of $E_{B}$ with the product of the respective percent of light transmission and the radiant exitance of the curing light (Table 4).

\section{Discussion}

This study investigated the changes of $\mathrm{VH}$ at the bottom surface of cured composite resins with respect to the radiosity measured from the same surface by MARC. In this experimental setup, the composite resin served as a barrier reducing the quantity of light energy exited the bottom surface. For each type of material investigated, the values of $\mathrm{VH}$ increased along with the radiosity initially until the hardness value eventually reached a plateau, the maximum $\mathrm{VH}$ value each respective material could reach. It is important to note that the regressions to determine the maximum $\mathrm{VH}$ values were conducted with data of all specimen thickness (Figures 1-3). In other words, the measured VH values were not dependent of the specimen thicknesses but related to radiosity at the bottom surface. For each

Table 2. Results of non-linear regression using eq. (1) showing the maximum hardness $(\alpha)$ and estimated radiosity at the bottom surface, when fraction of the maximum hardness is reached.

\begin{tabular}{lccccccc}
\hline \multirow{3}{*}{ Material } & \multicolumn{3}{c}{ Result of regression } & \multicolumn{4}{c}{ Estimated radiosity at fraction of maximum $\mathrm{VH}, \mathrm{J} / \mathrm{cm}^{2}$} \\
\cline { 2 - 8 } & $\alpha, \mathrm{kg} / \mathrm{mm}^{2}$ (mean $\left.\pm \mathrm{se}\right)$ & $\beta, \mathrm{J} / \mathrm{cm}^{2}$ (mean $\left.\pm \mathrm{se}\right)$ & $\mathrm{r}^{2}, \%$ & $80 \%$ & $90 \%$ & $95 \%$ & $99 \%$ \\
\hline SDR & $21.6 \pm 1.0$ & $0.40 \pm 0.06$ & 97.7 & 0.65 & 0.93 & 1.21 & 1.86 \\
TEC & $38.3 \pm 0.6$ & $0.77 \pm 0.04$ & 98.8 & 1.24 & 1.77 & 2.30 & 3.54 \\
EHD & $45.3 \pm 2.6$ & $0.58 \pm 0.09$ & 91.9 & 0.94 & 1.34 & 1.75 & 2.68 \\
\hline
\end{tabular}

Table 3. Results of linear regression of Radiosity (EB) vs radiant exposure time.

\begin{tabular}{lcccc}
\hline $\begin{array}{l}\text { Composite } \\
\text { resin }\end{array}$ & Thickness & Intercep & Slope & $\begin{array}{c}\text { Degree of } \\
\text { fit (\%) }\end{array}$ \\
\hline \multirow{3}{*}{ SDR } & $2 \mathrm{~mm}$ & -0.1820 & 0.3290 & 99.40 \\
& $4 \mathrm{~mm}$ & -0.0883 & 0.1668 & 99.39 \\
& $6 \mathrm{~mm}$ & -0.1699 & 0.0940 & 98.84 \\
TEX & $2 \mathrm{~mm}$ & -0.1592 & 0.1950 & 99.17 \\
& $4 \mathrm{~mm}$ & -0.0878 & 0.9005 & 99.77 \\
& $6 \mathrm{~mm}$ & -0.0431 & 0.0346 & 98.32 \\
EHD & $2 \mathrm{~mm}$ & -0.0566 & 0.0811 & 98.89 \\
& $4 \mathrm{~mm}$ & -0.0001 & 0.0190 & 99.99 \\
& $6 \mathrm{~mm}$ & -0.0001 & 0.0050 & 99.99 \\
\hline
\end{tabular}

Table 4. Estimated time required in seconds to deliver radiant exposure needed to polymerize composite resins to attain fraction of maximum hardness at each depth.

\begin{tabular}{lcccc}
\hline $\begin{array}{l}\text { Composite } \\
\text { resin }\end{array}$ & Thickness & Intercep & Slope & $\begin{array}{c}\text { Degree of } \\
\text { fit (\%) }\end{array}$ \\
\hline \multirow{3}{*}{ SDR } & $2 \mathrm{~mm}$ & -0.1820 & 0.3290 & 99.40 \\
& $4 \mathrm{~mm}$ & -0.0883 & 0.1668 & 99.39 \\
& $6 \mathrm{~mm}$ & -0.1699 & 0.0940 & 98.84 \\
TEC & $2 \mathrm{~mm}$ & -0.1592 & 0.1950 & 99.17 \\
& $4 \mathrm{~mm}$ & -0.0878 & 0.9005 & 99.77 \\
& $6 \mathrm{~mm}$ & -0.0431 & 0.0346 & 98.32 \\
EHD & $2 \mathrm{~mm}$ & -0.0566 & 0.0811 & 98.89 \\
& $4 \mathrm{~mm}$ & -0.0001 & 0.0190 & 99.99 \\
& $6 \mathrm{~mm}$ & -0.0001 & 0.0050 & 99.99 \\
\hline
\end{tabular}


material investigated the value of $\mathrm{VH}$ at the bottom surface attained its maximum when the radiosity exceeded a certain value and fluctuated within a range with additional radiant exposure. While the nonlinear regression of eq. (1) establishes the maximum $\mathrm{VH}$ values, it also shows mathematically that the maximum hardness can be reached only when the radiosity is infinite. It is, however, possible to calculate radiosity corresponding to any fraction of the maximum $\mathrm{VH}$, such as $80,90,95$ and $99 \%$, using eq. (1) and the values of $\alpha$ and $\beta$ in Table 2 . The calculated values of radiosity (Table 2), the radiant transmittance and the irradiance of the curing unit were then used to calculate the time needed to cure 2, 4 or $6 \mathrm{~mm}$ thick of composite resin specimens (Table 4 ).

$\mathrm{VH}$ profiles of all adequately cured composites would depict reducing $\mathrm{VH}$ values away from the surface of curing. ${ }^{20}$ Studies have shown that as the time of exposure time increases, a plateau of maximum $\mathrm{VH}$ within the upper portion of the specimen emerged and the thickness of the region depends on the material and the duration of curing., ${ }^{8,15}$ When it comes to determine the depth of cure by the $\mathrm{VH}$ profiles along the depth of a specimen, one school of thought is to accept the depth where the hardness value attains $80 \%$ of the maximum $\mathrm{VH}$ measured near the top surface exposed to light curing. ${ }^{21,22}$ In this study, maximum $\mathrm{VH}$ has been achieved at the bottom surface for all materials tested, the $80 \%$ rule, which use the hardness of top surface would not be meaningful. Should the approach used in this study become acceptable, a definitive number may be established for determining the depth of cure. Four levels of hardness at 80, 90, 95 and 99\% of the maximum $\mathrm{VH}$ were calculated to show the influence of the acceptance level on the time needed for curing, which can be used for comparison with the manufacturer's recommended curing time.

Manufacturers typically recommended a fixed curing time for each increment; some may specify minimal irradiance required for light curing units. For example, for 2-mm thick EHD the minimum radiant exitance must be at least $550 \mathrm{~mW} / \mathrm{cm}^{2}$ for 20-s exposure but could be reduced to $10 \mathrm{~s}$ with an advanced unit. Increments of TEC up to $4 \mathrm{~mm}$ can be polymerized in $10 \mathrm{~s}$ with radiant exitance greater than $1,000 \mathrm{~mW} / \mathrm{cm}^{2}$. For $4-\mathrm{mm}$ increment of SDR, $10 \mathrm{~s}$ could be indicated using radiant exitance greater than $1000 \mathrm{~mW} / \mathrm{cm}^{2}$. Several studies showed that after $20 \mathrm{~s}$ of curing both bulk-fill composites being investigated in the present study yielded satisfactory polymerization in depth over $4 \mathrm{~mm}$ with the minimum irradiation times stated by the manufacturers. ${ }^{6,7,13,23}$ With respect to EHD, the curing of 2-mm thick specimens for $20 \mathrm{~s}$ were reported to be satisfactory. ${ }^{24,25}$ These findings indicate that a 20 s curing using Bluephase 62 , which delivers irradiance higher than light-curing units used in those studies, should cure composite resins being investigated in this study adequately (Table 4 ).

The result showed that EHD, conventional regular composite resin, exhibited satisfactory polymerization in 2-mm increment with the minimum irradiation time stated by the manufacturer ( $20 \mathrm{~s}$ ) to obtain $80 \%$ of maximum hardness but not in the increment of $4 \mathrm{~mm}$. To achieve a satisfactory curing of $4 \mathrm{~mm}$ increment, a curing time of greater than $60 \mathrm{~s}$ is needed (Table 4), which is not practical clinically, and could endanger the, pulp by due to temperature rise for prolonged curing. ${ }^{26,27}$

The data (Table 4) show that all thicknesses of SDR, 2- and 4-mm for TEC and only 2-mm for EHD attained maximum $\mathrm{VH}$ within $60 \mathrm{~s}$ of curing. This behavior is also observed in the value of radiant transmittance (Table 4), which reflects the absorption and scattering of the light by the composite resins and is influenced by the composite formulation and thickness of the specimen as discussed. According to Table 4, a full $20 \mathrm{~s}$ of curing should yield a depth of cure slightly higher than $2 \mathrm{~mm}$ for EHD, between 4 and $5 \mathrm{~mm}$ with TEC and much higher than $6 \mathrm{~mm}$ with SDR. This finding is consistent with the results by Li et al. ${ }^{28}$ They used micro-Raman spectroscopy to examine degree of conversion of SDR and TEC after 20 of curing and reported that the effective depth of cure, which was defined as $90 \%$ of maximum degree of cure, to be $9.45 \mathrm{~mm}$ and $3.14 \mathrm{~mm}$, respectively. If a relationship between the specimen thickness and the time needed to cure the composite can be established for each material and the irradiance of the light curing unit, it would be possible to calculate the curing depth of the material for a prescribed time of curing.

The fact that the experimental data were consistent with the published data and the ability to estimate radiant exposure time needed to cure known thickness 
of composites resin may present this approach a viable method of characterizing curing properties of composite resins. The current approach has certain deficiency that requires attention. Two pieces of Mylar $^{\circledR}$ strips are often used to keep composite from contaminating the light sensor of MARC and protect the light emitting head of the curing light. Its effect on the radiant energy measurement could be small but needs to be quantified.

The use of pre-cured composite resin filled washer stacking on 1-mm washer filled with respective uncured composite resin was adopted to save the materials needed to conduct the work. It would be logical if the pre-cured composite resin subjected to radiant exposure behaves like fresh composite resin being cured. Study has shown after the polymerization phase, the light absorption and scattering of the composite changes because of the initiators are consumed and the refractive index of the matrix changes during polymerization. The former would decrease the absorption while the later could increase or decrease scattering depending on direction of the change of the refractive index relative to the fillers. ${ }^{29}$ Chen et al. reported that the absorption coefficient of freshly dispensed Z100 was higher than cured Z100. ${ }^{30}$ Review of the profiles of irradiance vs. time of curing as recorded by MARC showed that in the making of pre-cured discs there was a time lapse in reaching the plateau of maximum irradiance and no evidence of time lapse in the profile of irradiance profile over time in subsequent light curing. The lapse is the result of radiant exposure being utilized for activating the initiators and the length of lapse depends on the material and the thickness. It also means that when pre-cured discs were used to increase specimen thickness in place of fresh composite resins, the radiant exposure that would have been used for activating the initiators in fresh resin now became part of the radiosity measured by MARC. The immediate effect would be that the time shown in Table 4 would be shorter than that using all fresh composite resins. Nonetheless, the irradiance profiles also showed that the radiant exposure spent in the lapse phase constituted a small portion of the overall radiosity. The impact on the determination of maximum radiosity would be small. While we expect the difference to be minimal, the degree of difference could be addressed in further studies using fresh composite resins for all thickness.

Another potential issue that may arise is what could happen to the pre-cured composite resin discs after repeating radiant exposure and consequence on the radiosity recorded. For example, would they undergo further polymerization? Examination of these discs with Raman spectroscopy after so many repeating exposure may answer the question. There is temperature rise of the cured composite resin associated with radiant exposure of the composite. ${ }^{27}$ Repeated radiant exposure without adequate cooling period between experiments could bring the temperature of the disc even higher. The influence of such temperature elevation on the light transmission through pre-cured discs and the uncured composite is not known, even though abnormal temperature rise of the pre-cured discs was not observed during the experimental work. Should the pre-cured discs are to be used in the future studies; the protocol should attention to minimize the effect temperature rises.

\section{Conclusions}

All measured properties are significantly influenced by the material. Attenuation capacity among composite resin is different by the values of radiant transmittance. Increasing thickness of specimens did not affect the values of radiosity when adequate curing is achieved but require longer radiant exposure. The rate of reaching $\alpha$ as measured at the bottom of the cured composite was faster with flowable composite and became slower as the viscosity of the composite resin increased. Using a curing unit with known irradiance, the approach used in this study can be used to calculate the time needed to cure a known depth of restoration adequately or the depth of cure of a composite resin within a prescribed curing time.

\section{Acknowledgements}

Authors gratefully acknowledge Dentsply Caulk and Ivoclar Vivadent for donation of composite resins used in this study. 


\section{References}

1. Rodolpho PAR, Donassollo TA, Cenci MS, Loguércio AD, Moraes RR, Bronkhorst EM et al. 22-Year clinical evaluation of the performance of two posterior composites with different filler characteristics. Dent Mater. 2011t;27(10):955-63. https://doi.org/10.1016/j.dental.2011.06.001

2. Poskus LT, Placido E, Cardoso PEC. Influence of placement techniques on Vickers and Knoop hardness of class II composite resin restorations. Dent Mater. 2004;20(8):726-32. https://doi.org/10.1016/i.dental.2003.10.006

3. Garoushi S, Säilynoja E, Vallittu PK, Lassila L. Physical properties and depth of cure of a new short fiber reinforced composite. Dent Mater. 2013;29(8):835-41. https://doi.org/10.1016/j.dental.2013.04.016

4. Finan L, Palin WM, Moskwa N, McGinley EL, Fleming GJP. The influence of irradiation potential on the degree of conversion and mechanical properties of two bulk-fill flowable RBC base materials. Dent Mater. 2013;29(8):906-12. https://doi.org/10.1016/i.dental.2013.05.008

5. Dijken JW V, Pallesen U. A randomized controlled three year evaluation of "bulk-filled" posterior resin restorations based on stress decreasing resin technology. Dent Mater. 2014;30(9):e245-51. https://doi.org/10.1016/i.dental.2014.05.028

6. Benetti A, Havndrup-Pedersen C, Honoré D, Pedersen M, Pallesen U. Bulk-fill resin composites: polymerization contraction, depth of cure, and gap formation. Oper Dent. 2015;40(2):190-200. https://doi.org/10.2341/13-324-L

7. Jang JH, Park SH, Hwang IN. Polymerization shrinkage and depth of cure of bulk-fill resin composites and highly filled flowable resin. Oper Dent. 2015;40(2):172-80. https://doi.org/10.2341/13-307-L

8. Czasch P, llie N. In vitro comparison of mechanical properties and degree of cure of bulk fill composites. Clin Oral Investig. 2013;17(1):227-35. https://doi.org/10.1007/s00784-012-0702-8

9. Leprince JG, Palin WM, Vanacker J, Sabbagh J, Devaux J, Leloup G. Physico-mechanical characteristics of commercially available bulk-fill composites. J Dent. 2014;42(8):993-1000. doi:10.1016/i.jdent.2014.05.009. https://doi.org/10.1016/j.jdent.2014.05.009

10. Kumagai RY, Zeidan LC, Rodrigues JA, Reis AF, Roulet JF. Bond strength of a flowable bulk-fill resin composite in Class II MOD cavities. J Adhes Dent. 2015;17(5):427-32. https://doi.org/10.3290/i.jad.a35012

11. Garcia D, Yaman P, Dennison J, Neiva GF. Polymerization shrinkage and depth of cure of bulk fill flowable composite resins: commentary. J Esthet Restor Dent. 2015;27(4):232-3.

12. Reis AF, Vestphal M, Rodrigues JA, Roulet JF, Roscoe MG. Efficiency of polymerization of bulk-fill composite resins: a systematic review. Braz Oral Res. 2017;31 Suppl:59. https://doi.org/10.1590/1807-3107BOR-2017.vol31.0059
13. Goracci C, Cadenaro M, Fontanive L, Giangrosso G, Juloski J, Vichi A et al. Polymerization efficiency and flexural strength of low-stress restorative composites. Dent Mater. 2014;30(6):688-94. https://doi.org/10.1016/i.dental.2014.03.006

14. Alshali RZ, Silikas N, Satterthwaite JD. Degree of conversion of bulk-fill compared to conventional resin-composites at two time intervals. Dent Mater. 2013;29(9):e213-7. https://doi.org/10.1016/j.dental.2013.05.011

15. Ilie N, Keßler A, Durner J. Influence of various irradiation processes on the mechanical properties and polymerisation kinetics of bulk-fill resin based composites. J Dent. 2013;41(8):695-702. https://doi.org/10.1016/i.jdent.2013.05.008

16. Tarle Z, Attin T, Marovic D, Andermatt L, Ristic M, Tauböck TT. Influence of irradiation time on subsurface degree of conversion and microhardness of high-viscosity bulk-fill resin composites. Clin Oral Investig. 2015;19(4):831-40. https://doi.org/10.1007/s00784-014-1302-6

17. Calheiros FC, Kawano Y, Stansbury JW, Braga RR. Influence of radiant exposure on contraction stress, degree of conversion and mechanical properties of resin composites. Dent Mater. 2006;22(9):799-803 https://doi.org/10.1016/j.dental.2005.11.008

18. Fan PL, Schumacher RM, Azzolin K, Geary R, Eichmiller FC. Curing-light intensity and depth of cure of resin-based composites tested according to international standards. J Am Dent Assoc. 2002;133(4):429-34. https://doi.org/10.14219/jada.archive.2002.0200

19. Price RB, McLeod ME, Felix CM. Quantifying light energy delivered to a Class I restoration. J Can Dent Assoc. 2010;76:a23.

20. Flury S, Hayoz S, Peutzfeldt A, Hüsler J, Lussi A. Depth of cure of resin composites: is the ISO 4049 method suitable for bulk fill materials? Dent Mater. 2012;28(5):521-8. https://doi.org/10.1016/j.dental.2012.02.002

21. Marovic D, Panduric V, Tarle Z, Ristic M, Sariri K, Demoli N et al. Degree of conversion and microhardness of dental composite resin materials. J Mol Struct. 2013;1044:299-302. https://doi.org/10.1016/j.molstruc.2012.10.062

22. Tauböck TT, Zehnder M, Schweizer T, Stark WJ, Attin T, Mohn D. Functionalizing a dentin bonding resin to become bioactive. Dent Mater. 2014;30(8):868-75. https://doi.org/10.1016/i.dental.2014.05.029

23. Flury S, Peutzfeldt A, Lussi A. Influence of increment thickness on microhardness and dentin bond strength of bulk fill resin composites. Dent Mater. 2014;30(10):1104-12. https://doi.org/10.1016/i.dental.2014.07.001

24. Lombardini M, Chiesa M, Scribante A, Colombo M, Poggio $C$. Influence of polymerization time and depth of cure of resin composites determined by Vickers hardness. Dent Res J (Isfahan). 2012;9(6):735-40. 
25. Francis AV, Braxton AD, Ahmad W, Tantbiroin D, Simon JF, Versluis A. Cuspal flexure and extent of cure of a bulk-fill flowable base composite. Oper Dent. 2015;40(5):515-23. https://doi.org/10.2341/14-235-L

26. Hussey DL, Biagioni PA, Lamey PJ. Thermographic measurement of temperature change during resin composite polymerization in vivo. J Dent. 1995;23(5):267-71. https://doi.org/10.1016/0300-5712(95)91149-H

27. Uhl A, Mills RW, Jandt KD. Polymerization and light-induced heat of dental composites cured with LED and halogen technology. Biomaterials. 2003;24(10):1809-20. https://doi.org/10.1016/S0142-9612(02)00585-9
28. Li X, Pongprueksa P, Van Meerbeek B, De Munck J. Curing profile of bulk-fill resin-based composites. J Dent. 2015;43(6):664-72. https://doi.org/10.1016/i.jdent.2015.01.002

29. Sidhu SK, Ikeda T, Omata Y, Fujita M, Sano H. Change of color and translucency by light curing in resin composites. Oper Dent. 2006;31(5):598-603. https://doi.org/10.2341/05-109

30. Chen YC, Ferracane JL, Prahl SA. A pilot study of a simple photon migration model for predicting depth of cure in dental composite. Dent Mater. 2005;21(11):1075-86. https://doi.org/10.1016/i.dental.2005.05.00 